\title{
An evaluation of the International Standards to Document Remaining Autonomic Function after Spinal Cord Injury: input from the international community
}

\author{
AM Round ${ }^{1,2}$, SE Park ${ }^{3,4}$, K Walden 3 , VK Noonan ${ }^{3,4}$, AF Townson ${ }^{5,6}$ and AV Krassioukov ${ }^{1,5,6}$
}

Study design: Interactive workshops with a presurvey-postsurvey.

Objectives: To describe a series of workshops held at international meetings to inform the spinal cord injury (SCl) community about the International Standards to Document Remaining Autonomic Function after Spinal Cord Injury (ISAFSCI) and to obtain feedback on both the workshop and the ISAFSCI assessment.

Setting: Three international conferences of SCI practitioners in Toronto, Las Vegas and Vancouver held between 2012 and 2013.

Methods: The workshops included an overview of the ISAFSCI, sharing experiences using it in clinical practice and interactive cases illustrating how to complete the scoring. A presurvey-postsurvey was administered to obtain feedback on the workshops and the ISAFSCI assessment.

Results: One hundred and fourteen participants completed the workshop surveys and 96\% (109/114) completed both presurvey and postsurvey. Prior to the workshop, 41\% (47/114) of those who had completed the survey reported assessing autonomic function in their practice, and of those, 53\% (25/47) reported using the ISAFSCI. After the workshop, 74\% (84/114) of participants reported that the case studies were helpful, and 57\% (65/114) reported that they wanted to start or continue to use the ISAFSCI in their clinical practice. Suggestions for improving the ISAFSCI included providing further areas to consider when performing the assessment, addressing ambiguity of terms and reporting foreseeable implementation challenges.

Conclusion: Results from this workshop suggest that more work is needed to inform the $\mathrm{SCl}$ community on the ISAFSCI assessment and to further clarify its language. Results from this study will inform future revisions to the ISAFSCI.

Spinal Cord (2017) 55, 198-203; doi:10.1038/sc.2016.152; published online 29 November 2016

\section{INTRODUCTION}

Following a spinal cord injury (SCI), supraspinal control of bodily organs is partially or completely impaired. This leads not only to motor paralysis and sensory changes but also to various autonomic dysfunctions, including bowel, bladder and sexual dysfunction, abnormal blood pressure and heart rate control and sweating and temperature dysregulation. ${ }^{1,2}$ These autonomic dysfunctions result in a significant burden to persons with SCI, their family members and the health-care system in terms of reduced participation in activities of daily life, ${ }^{3}$ barriers to employment ${ }^{4}$ and lower quality of life. ${ }^{5}$ In a recent survey by Anderson, ${ }^{6}$ persons with SCI ranked regaining bladder and bowel function as a high priority, surpassing regaining the ability to walk. A tool for measuring the extent of impairment is crucial to make accurate judgments on functional ability and tailor the individual's care plan accordingly. Although measuring motor and sensory impairment following SCI is now widely carried out using the International Standards for Neurological Classification of Spinal Cord Injury (ISNCSCI), ${ }^{7}$ an analogous measure for assessing the autonomic nervous system was not previously available.
To address this significant gap, the American Spinal Injury Association (ASIA) and the International Spinal Cord Society (ISCoS) assembled a working group in 2007 with the task of creating international standards. The first version of the International Standards to Document Remaining Autonomic Function after Spinal Cord Injury, a standardized autonomic assessment to complement ISNCSCI, was created and published in Spinal Cord in 2009 as a collective international effort of that working group. ${ }^{2}$ In 2012, this document was revised and a second edition of the International Standards to Document Remaining Autonomic Function after Spinal Cord Injury (ISAFSCI) was published. ${ }^{8}$ Presently, the ISAFSCI table is freely available on the ASIA and ISCoS websites. ${ }^{9}$

Experience with the ISNCSCI has demonstrated the importance of training and education to improve completing the assessment regardless of the examiner's experience. ${ }^{10,11} \mathrm{~A}$ recent study by Liu et al..$^{12}$ illustrated that attending a workshop on the ISNCSCI which included case studies was superior to reading the information booklet alone in learning how to correctly classify SCI using ISNCSCI. As a result, a similar approach to training and education was

${ }^{1}$ International Collaboration on Repair Discoveries (ICORD), Vancouver, British Columbia, Canada; ${ }^{2}$ Department of Medicine, University of British Columbia, Vancouver, British Columbia, Canada; ${ }^{3}$ Rick Hansen Institute, Vancouver, British Columbia, Canada; ${ }^{4}$ Department of Orthopedics, University of British Columbia, Vancouver, British Columbia, Canada; ${ }^{5}$ Department of Medicine, Division of Physical Medicine and Rehabilitation, University of British Columbia, Vancouver, British Columbia, Canada and ${ }^{6}$ GF Strong Rehabilitation Centre, Vancouver Health Authority, Vancouver, British Columbia, Canada

Correspondence: Dr AV Krassioukov, Department of Medicine, ICORD-BSCC, UBC, 818 West 10th Avenue, Vancouver, British Columbia V5Z 1M9, Canada.

E-mail: krassioukov@icord.org

Received 12 November 2015; revised 27 April 2016; accepted 2 May 2016; published online 29 November 2016 
developed for the ISAFSCI including a website with an online educational module called Autonomic Standards Training E Program $(\mathrm{ASTeP})^{13}$ and a workshop to teach the ISAFSCI. Presently, only limited data are available on the use of ISAFSCI in the community. ${ }^{14}$

The objectives of this study were to describe data obtained during a series of workshops held at international meetings to inform the SCI research and clinical community on the structure and application of the ISAFSCI in clinical practice and research and to obtain feedback on both the workshop and utility of the ISAFSCI assessment from participants who had already started to apply this tool in their practice.

\section{METHODS}

\section{Overview of the ISAFSCI}

The ISAFSCI is a tool to be used by health-care practitioners and researchers in the context of SCI as an objective means to bring autonomic dysregulation to clinical awareness, ensure a standardized and validated approach to describing autonomic dysfunction in SCI and to monitor progress when performed serially. Ideally, the ISAFSCI and the ISNCSCI would be used together to encourage complete evaluation of the spinal cord-injured patient. The ISAFSCI is categorized by organ system that includes: autonomic control of the heart, blood pressure, sweating, temperature regulation, breathing, lower urinary tract, bowel function and sexual function. In each of these areas, specific clinical abnormalities are inquired of and classified such as a persistent bradycardia, for example. Urodynamics was a component of the previous edition of the ISAFSCI but was removed for technical reasons; however, it is encouraged to use the International SCI urodynamic basic data set for a complete autonomic evaluation. ${ }^{15}$

Unlike the ISNCSCI that is based entirely on a physical examination, the ISAFSCI includes the patient's subjective information as well as findings from a physical examination as can be seen in Figure 1. The ISAFSCI has two components, each with a different scoring system. Part one includes a description of the remaining general autonomic function and is scored by selecting the appropriate category to indicate if it is 'normal', 'abnormal', 'unknown' or 'unable to assess'. Definitions of terms such as cardiac dysrhythmias are included in the booklet (for example, bradycardia is $<60$ beats per minute, tachycardia is $>100$ beats per minute) to help the examiner select the appropriate category. Part two assesses urinary, bowel and sexual function and is completed by asking the patient to rate his or her symptoms from 0 to 2, where 2 is what the patient perceives as a 'normal function' and 0 is a 'complete loss of function'. 'NT' (not testable) is scored when the symptom cannot be assessed owing to preexisting or concomitant problems.

\section{Overview of the workshops}

Workshops were held at three international meetings of the SCI practitioners: the Fifth National SCI conference held in Toronto, October 2012; the Academy of Spinal Cord Injury Professionals (ASCIP) held in Las Vegas, October 2013; and the Second International Autonomic Symposium held in Vancouver, November 2013. These meetings typically bring together clinicians and scientists with expertise and interests in the area of SCI research and medicine. The goals of the workshops were: to educate the SCI community on the need to assess autonomic functions using the ISAFSCI, to present clinical cases to assist in completing the ISAFSCI scoring accurately, and to receive feedback on the ISAFSCI assessment.

The workshop presentation started with background information on the ISAFSCI, its origin, challenges and current direction. Experience using the ISAFSCI in a Canadian tertiary rehabilitation center as well as information on the reliability and validity of the ISAFSCI were shared. ${ }^{14}$ Sample cases were presented followed by an interactive session where participants were asked to complete the ISAFSCI using a case study and given a chance to ask the speaker's questions.

\section{Design and administration of presurvey/postsurvey}

A survey was drafted by the workshop organizers who had experience using the ISAFSCI and conducting educational workshops. The participants were asked to fill out a two-part survey before and after the workshop. The presurvey contained a total of five questions (one question had seven response options, three questions had Yes/No response options and one was free text). The content included the participant's professional training, experience with conducting an autonomic assessment and ISAFSCI as well as expectations regarding the workshop. The postsurvey contained seven questions (four questions had five response options, one question had Yes/No response options and two were free text). The survey asked about the relevance of the workshop materials, the participant's confidence and planned use of the ISAFSCI in their clinical practice and feedback on the ISASFSCI assessment.

\section{Data analysis}

Data from the presurvey and postsurvey for all three workshops were combined and analyzed using descriptive statistics. Written feedback obtained as a part of the postsurvey was reviewed to identify common themes and then grouped accordingly.

\section{RESULTS}

\section{Participant demographics and autonomic assessment}

A total of 114 participants completed the workshop presurvey and postsurvey. Of those, 109 participants (96\%) completed at least one question from both surveys. The first question of the presurvey asking about the participant's professional training was added after the first workshop, so only 77 responses were obtained for that question. The demographics for attendees are as follows: physiatrists $(49 \%, 38 / 77)$, nurses $(10 \%, 8 / 77)$, occupational therapists $(6 \%, 5 / 77)$, physical therapists $(8 \%, 6 / 77)$, researchers $(14 \%, 11 / 77)$, and 'other clinical' $(12 \%, 9 / 77)$. Prior to the workshop, $41 \%(47 / 114)$ of the participants reported assessing autonomic function in their practice, and of those who did, 53\% use the ISAFSCI (25/47). Only 28\% (13/47) reported that they had completed the ASIA web-based training ASTeP prior to the workshop (http://lms3.learnshare.com/home.aspx).

\section{Comment analysis}

Comments from the postsurvey regarding the ISAFSCI were grouped into three themes: system/organ content, measurement, and administration and relevance. An overview of responses is available in Table 1. The 'system/organ content theme' included comments related to a specific organ or organ system assessed in the ISAFSCI, which included autonomic control of the heart and blood pressure, sweating and temperature regulation, broncho-pulmonary system and lower urinary tract and sexual functions. There were three comments related to autonomic control of sweating (for example, 'does not address unilateral sweating'). Some participants did not understand the question related to sexual dysfunction (for example, 'what is sensation of menses') and coding for instrumentation of the lower urinary tract (for example, 'still not entirely clear how to [code] if Foley [is] present)'.

The 'measurement theme' included comments on how to code and interpret the ISAFSCI. Some comments suggested the need for standardized questions and a summary score. From the postsurvey, $82 \%(94 / 114)$ of the participants felt it would be helpful or very helpful (score 4 or 5 out of 5 ) if the abnormal conditions included in the ISAFSCI were defined on the assessment form. Several participants suggested adding more details to describe autonomic functions (for example, 'unsure of the details regarding definitions or some of the dysfunctions').

The 'administration and relevance theme' included comments regarding conducting the actual assessment and establishing a rationale for implementing the ISAFSCI. There were 20 comments in this section, which had the most comments among the three themes. The most common feedback was related to the challenges 


\section{Autonomic Standards Assessment Form}

Patient Name:

\section{General Autonomic Function}

\begin{tabular}{|c|c|c|c|}
\hline System/Organ & Findings & Abnormal conditions & $\begin{array}{l}\text { Check } \\
\text { mark }\end{array}$ \\
\hline \multirow{6}{*}{$\begin{array}{l}\text { Autonomic } \\
\text { control of the } \\
\text { heart }\end{array}$} & Normal & & \\
\hline & \multirow[t]{3}{*}{ Abnormal } & Bradycardia & \\
\hline & & Tachycardia & \\
\hline & & Other dysrhythmias & \\
\hline & Unknown & & \\
\hline & \begin{tabular}{|l} 
Unable to \\
assess
\end{tabular} & & \\
\hline \multirow{6}{*}{$\begin{array}{l}\text { Autonomic } \\
\text { control of } \\
\text { blood } \\
\text { pressure }\end{array}$} & Normal & & \\
\hline & \multirow[t]{3}{*}{ Abnormal } & $\begin{array}{l}\text { Resting systolic blood pressure } \\
\text { below } 90 \mathrm{mmHg}\end{array}$ & \\
\hline & & Orthostatic hypotension & \\
\hline & & Autonomic dysreflexia & \\
\hline & Unknown & & \\
\hline & $\begin{array}{l}\text { Unable to } \\
\text { assess }\end{array}$ & & \\
\hline \multirow{6}{*}{$\begin{array}{l}\text { Autonomic } \\
\text { control of } \\
\text { sweating }\end{array}$} & Normal & & \\
\hline & \multirow[t]{3}{*}{ Abnormal } & Hyperhydrosis above lesion & \\
\hline & & Hyperhydrosis below lesion & \\
\hline & & Hypohydrosis below lesion & \\
\hline & Unknown & & \\
\hline & $\begin{array}{l}\text { Unable to } \\
\text { assess }\end{array}$ & & \\
\hline \multirow{5}{*}{$\begin{array}{l}\text { Temperature } \\
\text { regulations }\end{array}$} & Normal & & \\
\hline & \multirow[t]{2}{*}{ Abnormal } & Hyperthermia & \\
\hline & & Hypothermia & \\
\hline & Unknown & & \\
\hline & $\begin{array}{l}\text { Unable to } \\
\text { assess }\end{array}$ & & \\
\hline \multirow{6}{*}{\begin{tabular}{|l|} 
Autonomic and \\
Somatic Control \\
of Broncho- \\
pulmonary \\
System
\end{tabular}} & Normal & & \\
\hline & \multirow[t]{3}{*}{ Abnormal } & \begin{tabular}{|l} 
Unable to voluntarily breathe \\
requiring full ventilatory support
\end{tabular} & \\
\hline & & \begin{tabular}{|l|} 
Impaired voluntary breathing \\
requiring partial vent support
\end{tabular} & \\
\hline & & \begin{tabular}{|l|} 
Voluntary respiration impaired \\
does not require vent support \\
\end{tabular} & \\
\hline & Unknown & & \\
\hline & $\begin{array}{l}\text { Unable to } \\
\text { assess }\end{array}$ & & \\
\hline
\end{tabular}

Figure 1 Current ISAFSCI Assessment Form.

with implementing the ISAFSCI: participants commented that it was not clear how to implement (for example, 'I'm still wondering who would complete [the assessment]') and that the attempt to change current practice would face resistance from members of the clinical team (for example, 'this would be a point of contention with the attending physician').

Feedback on workshop content and structure

The general feedback on the workshop content and structure was positive. The postsurveys revealed that $72 \%(82 / 114)$ and $74 \%$ (84/114) of participants reported that the lecture and case study portion of the workshop, respectively, to be helpful or very helpful (score 4 or 5 out of 5). In all, $42 \%$ (48/114) of participants felt confident or very confident (score 4 or 5 out of 5 ) in using ISAFSCI after participating in the workshop and 57\% (65/114) reported a
Autonomic Diagnosis: (Supraconal $\square$, Conal $\square$, Cauda Equina $\square$ )

\section{Lower Urinary Tract, Bowel and Sexual Function}

\begin{tabular}{|c|c|c|}
\hline System/Organ & & Score \\
\hline \multicolumn{3}{|l|}{ Lower Urinary Tract } \\
\hline \multicolumn{2}{|l|}{ Awareness of the need to empty the bladder } & \\
\hline \multicolumn{2}{|l|}{ Ability to prevent leakage (continence) } & \\
\hline \multicolumn{2}{|l|}{ Bladder emptying method (specify) } & \\
\hline \multicolumn{3}{|l|}{ Bowel } \\
\hline \multicolumn{2}{|l|}{ Sensation of need for a bowel movement } & \\
\hline \multicolumn{2}{|c|}{ Ability to Prevent Stool Leakage (continence) } & \\
\hline \multicolumn{2}{|l|}{ Voluntary sphincter contraction } & \\
\hline \multicolumn{3}{|l|}{ Sexual Function } \\
\hline \multirow[t]{2}{*}{ Genital arousal (erection or lubrication) } & Psychogenic & \\
\hline & Reflex & \\
\hline \multicolumn{2}{|l|}{ Orgasm } & \\
\hline \multicolumn{2}{|l|}{ Ejaculation (male only) } & \\
\hline Sensation of Menses (female only) & & \\
\hline
\end{tabular}

$2=$ Normal function, $1=$ Reduced or Altered Neurological Function $0=$ Complete loss of control, $\mathrm{NT}=$ Unable to assess due to preexisting or concomitant problems

Date of Injury Date of Assessment

This form may be freely copied and reproduced but not modified. This assessment should use the terminology found in the International SCI Data Sets (ASIA and ISCOS- http://www.iscos.org.uk)

Examiner

desire to either start or continue using the ISAFSCI autonomic assessment form as part of their practice. From the comments in the postsurvey, most participants reported satisfaction with the workshop (for example, 'I'm happy with the session', 'case studies were good', 'great presentations'). There was a lot of support for reducing the didactic component of the workshop and spending more time on case studies and making the cases more complex (for example, 'perhaps less focus on the lecture component and more focus on cases', 'longer time on case studies', 'a more intricate case study', 'perhaps listing full case history and allowing audience to fill out the entire scale').

\section{DISCUSSION}

Overall, the goals of the workshops were achieved, which were to raise awareness of the ISAFSCI, present clinical cases to assist participants 
Table 1 Summary of the feedback regarding the ISAFSCI content and administration

\begin{tabular}{|c|c|c|}
\hline A: System/organ content feedback & B: Measurement feedback & C: Administration and relevance \\
\hline $\begin{array}{l}\text { a: Autonomic control of sweating (3) } \\
\text { "What about Homer's syndrome?" }\end{array}$ & $\begin{array}{l}\text { a: Ambiguity of terms or revising questions used to collect } \\
\text { information (9) } \\
\text { "I think clarifying definitions would help. Possible removing }\end{array}$ & $\begin{array}{l}\text { a: Implementation challenges (9) } \\
\text { "Challenging to implement this tool as } \\
\text { part of clinical practice" }\end{array}$ \\
\hline $\begin{array}{l}\text { b: Autonomic control of lower urinary tract ( } 3 \text { ) } \\
\text { "When do you give [normal] to bladder sensation and } \\
\text { [impaired function] - How to differentiate?" }\end{array}$ & $\begin{array}{l}\text { below/above lesion definitions might improve clarity." } \\
\text { "How to ask questions about sexual dysfunction should be } \\
\text { standardized" }\end{array}$ & $\begin{array}{l}\text { "It would have to be discussed with team } \\
\text { members and change documentation" }\end{array}$ \\
\hline $\begin{array}{l}\text { c: Autonomic control of sexual function (3) } \\
\text { "Not all patients interpret the questions the same. }\end{array}$ & $\begin{array}{l}\text { b: Definitions for normal and abnormal need to be defined on } \\
\text { assessment form (2) }\end{array}$ & $\begin{array}{l}\text { b: Assessment form's visual needs } \\
\text { improvement (4) } \\
\text { "I would consider shading out the score }\end{array}$ \\
\hline This is particularly difficult in this domain." & $\begin{array}{l}\text { "I think that it will be hard to have widespread consistency until } \\
\text { [abnormal conditions are defined on the assessment form]" }\end{array}$ & $\begin{array}{l}\text { box by the bladder emptying method } \\
\text { question." }\end{array}$ \\
\hline d: Autonomic control of temperature regulation (2) & & \\
\hline $\begin{array}{l}\text { "I'm confused about hyper/hypothermia - with some } \\
\text { patients their body temp depends on environmental } \\
\text { temperature" }\end{array}$ & $\begin{array}{l}\text { c: Creating a summary score (2) } \\
\text { "I would like to use the ISAFSCI to get a summary/classification } \\
\text { of the autonomic function for my patients (similar to ISNCSCI) } \\
\text { instead of a list of answers to a variety of autonomic function }\end{array}$ & $\begin{array}{l}\text { c: Relevance of using the standard ques- } \\
\text { tionable (4) } \\
\text { "Not sure if possible-appears to be more } \\
\text { of a research tool presently" }\end{array}$ \\
\hline e: Autonomic control of blood pressure (2) & questions in a variety of areas" & \\
\hline $\begin{array}{l}\text { "What is the definition of hypertension in SCI } \\
\text { patients?" }\end{array}$ & "Summary score? Score to indicate degree of abnormality?" & $\begin{array}{l}\mathrm{d}: \text { Not enough time (2) } \\
\text { "Time constraint" } \\
\text { "Don't have time to fully administer" }\end{array}$ \\
\hline f: Autonomic and somatic control of bronchopulmonary & & \\
\hline $\begin{array}{l}\text { system (1) } \\
\text { "Understanding of the standards. What about }\end{array}$ & & e: Reliability of the standard questionable (1) \\
\hline increased respiratory secretion production?" & & $\begin{array}{l}\text { "Not confident - as consistency/ } \\
\text { reliability" }\end{array}$ \\
\hline $\begin{array}{l}\text { g: Autonomic control of the heart (1) } \\
\text { "Still not entirely clear what to do with bradycardia } \\
\text { only with } A D \text { " }\end{array}$ & & \\
\hline
\end{tabular}

with completing the assessment, receive feedback on the ISAFSCI assessment and evaluate the workshops. The workshops also served as a mechanism to obtain feedback on potential challenges with implementing the ISAFSCI.

\section{Addressing ambiguity in language and coding rules}

Feedback included in the 'system/organ content' and the 'measurement' themes highlighted the need for clearer definitions and standardized statements that can be used to administer the questions. In particular, $82 \%(94 / 114)$ of the participants felt it would be beneficial (score 4 or 5 out of 5 on the question) to have a definition of 'abnormal conditions' on the assessment form (for example, 'what is meant by abnormal condition. SCI is abnormal', Definition of hypertension in SCI patients [is needed]'). Confusion resulting from the term 'abnormal' has occurred previously in SCI. Persons with SCI report encountering a similar problem when completing a general health measure such as the Short Form-36 as the questions are asked in the context of how their health limits them. ${ }^{16}$ Not all individuals consider having an SCI as impacting their health, as individuals may have an SCI but are healthy, whereas others considered their SCI as part of their overall health and answered the questions differently. ${ }^{17}$ An SCI-specific definition of what is considered 'normal' listed on the assessment form as well as specific examples to clarify terms such as 'sexual dysfunction' would be helpful in obtaining more consistent answers.
The international SCI research community under the guidance of ISCoS has formed numerous data sets with the aim of standardizing the collection of data pertaining to SCI. These data sets attempt to quantify various SCI domains similar to ISAFSCI such as cardiopulmonary, bowel, bladder and sexual functions through preset questions and discrete answers. These data sets have been official since 2006 from the initial publication, are regularly being improved upon and can be accessed at http://www.iscos.org.uk/international-scidata-sets. ${ }^{18}$ ISFASCI has been developed alongside these data sets but functions distinctly to provide assessment and monitoring of an individual's autonomic functioning after SCI; the data sets, however, are for standardizing the information collected in a research setting to promote both clinicians and researchers communicating in similar terms. Despite these differences, the data sets are useful to those using ISAFSCI in the clinical setting to shed light on approaching these difficult-to-define terms in the context of SCI and its effects on the various organ systems.

\section{Addressing concerns and challenges with implementing ISAFSCI in clinical practice}

The most frequent comment in the administration and relevance theme' was the expected challenges in implementing the ISAFSCI in clinical practice. In the postsurvey, only 57\% (65/114) of the participants reported that they will continue to use or plan to use the ISAFSCI in their practice. Although there is no similar question in the presurvey to examine the change in attitude with the workshop, 
this number may be lower than expected owing to the participants' concern with the feasibility of implementation and lack of confidence in performing the assessment that is further explored in the next section. Leadership from program administration as well as the clinical team members who are knowledgeable and supportive would be crucial to facilitate the implementation. ${ }^{19}$ To facilitate the implementation of the ISAFSCI in Canada, projects such as the Spinal Cord Research Evidence (http://www.scireproject.com) are creating information sheets for clinicians to help with the collection of the ISAFSCI and SCI experts in Canada ensured that the Accreditation Canada SCI Standards ${ }^{20}$ included recommendations that autonomic function needs to be assessed utilizing a measure such as ISAFSCI. Furthermore, indicators monitoring both the utilization of the ISFASCI (process indicator) and the results of the assessment (outcome indicator) will be incorporated into the Rick Hansen SCI Registry $^{21}$ to promote adoption in all Canadian SCI centers and to facilitate future research in this area. This is just one example of how the assessment of autonomic assessment is being implemented into clinical practice that could serve as a model for other countries.

\section{Addressing low level of confidence in performing autonomic assessments}

With only $42 \%(48 / 114)$ of the participants rating themselves as confident or very confident (score 4 or 5 out of 5 ) in performing the ISAFSCI in the postsurvey, it is clear that workshop alone is not sufficient to train participants. Previous studies have all reported that training improves the accuracy of ISNCSCI classification and does not depend on the training method. ${ }^{11,12,22,23}$ Examples of training methods used include: an instructional course during annual conference meetings ${ }^{22}$; a formal training session composed of lectures, video on testing technique and hands-on practice with immediate feedback from the instructor ${ }^{23}$; formal presentations and case reviews followed by discussion ${ }^{11}$; and self-learning and case studies. ${ }^{12}$ ASTeP is a free online resource that could be used to enhance understanding on autonomic dysfunction after SCI but was only completed before the workshop by $18 \%(20 / 114)$ of the participants. ${ }^{13}$ Currently, ASTeP does not include training modules teaching the ISAFSCI assessment similar to ISNCSCI as part of INSTeP. ${ }^{24}$ Actively disseminating ASTeP to clinicians as well as including a training module on the ISAFSCI assessment with case studies to ASTeP may enhance the clinicians' expertise and confidence in administering the ISAFSCI.

\section{Future directions}

Providing interactive workshops is useful in increasing awareness about the importance of assessing autonomic dysfunctions post-SCI and introducing the ISAFSCI. The suggestion to host more of such workshops in the future will be discussed by the Autonomic Standards Committee. Furthermore, feedback on the content of the ISAFSCI standards will be considered when updating for the next edition. There will be a focus on making the terms as clear as possible and the questions standardized for improved validity among other changes. Currently, a study is in progress to assess the reliability of the standards and to assess the construct validity in two centers in Canada. These two studies will provide insights to revise the ISAFSCI for future revisions.

\section{Study limitations}

In considering the results from this study, it is important to recognize the limitations. First, all of the workshops were conducted in Canada and United States that may potentially limit obtaining feedback from clinicians and researchers from other countries. The third workshop was held during the Second International Autonomic Symposium, which was attended by experts from around the world, but future workshops should be hosted during ISCoS to promote more international attendance. It is also worth noting that the attendees were self-selected based on interest in autonomic dysfunction thus making it difficult to comment on the interest of and relevance to general practitioners. Second, it is not possible to determine the response rate for completing the presurvey and postsurvey as a registration log was not kept for the workshops to document the total number of completed surveys. As there is no way of ensuring that the participants who have turned in the survey are representative of the group who have attended the workshop, our result is subjected to a potential sampling bias. Third, questions from the presurvey and postsurvey were different, which made it impossible to measure the change in participant attitude from attending and completing the workshop. Finally, it is not known if the participants who reported that they intended to implement the ISFASCI upon returning to practice actually did. Future endeavors should focus on fostering collaboration among the individuals who have expressed interest and assist them in operationalizing the implementation into the clinical practice, where practice change and patient benefit could be achieved.

\section{CONCLUSION}

Similar to the history of the ISNCSCI, the ISAFSCI will require further research and discussion on how best to measure autonomic function following SCI. The ISAFSCI assesses vital body functions and these are of great importance to persons with SCI. Future studies providing information on the psychometric properties of the ISAFSCI will further elucidate how best to revise it. Furthermore, studies examining how to incorporate the ISAFSCI into clinical practice and use the results to inform decision-making will make it a critical component in the assessment and management of persons with SCI.

\section{DATA ARCHIVING}

There were no data to deposit.

\section{CONFLICT OF INTEREST}

So Eyun Park, Kristen Walden and Vanessa K Noonan are employees of Rick Hansen Institute. The remaining authors declare no conflict of interest.

\section{ACKNOWLEDGEMENTS}

We thank the contributions made by the workshop participants. This study was supported by a grant from Rick Hansen Institute, Health Canada and Western Economic Diversification Canada.

1 Burns S, Biering-Sørensen F, Donovan W, Graves DE, Jha A, Johansen M et al. International standards for neurological classification of spinal cord injury, revised 2011. Top Spinal Cord Inj Rehabil 2012; 18: 85-99.

2 Alexander MS, Biering-Sorensen F, Bodner D, Brackett NL, Cardenas D, Charlifue S et al. International standards to document remaining autonomic function after spinal cord injury. Spinal Cord 2009; 47: 36-43.

3 Cobb J, Dumont FS, Leblond J, Park SE, Noonan VK, Noreau L. An exploratory analysis of the potential association between $\mathrm{SCl}$ secondary health conditions and daily activities. Top Spinal Cord Inj Rehabil 2014; 20: 277-288.

4 Escorpizo R, Miller W, Trenaman L, Smith E. In:Eng J, Teasell R, Miller W, Wolfe D, Townson A, Hsieh J et al. (eds). Spinal Cord Injury Rehabilitation Evidence, 5.0 edn, 2014 p 1-22.

5 Noonan V, Fallah N, Park S, Dumont F, Leblond J, Cobb J et al. Health care utilization in persons with traumatic spinal cord injury: the importance of multimorbidity and the impact on patient outcomes. Top Spinal Cord Inj Rehabil 2014; 20: 289-301.

6 Anderson K. Targeting recovery: priorities of the spinal cord-injured population. J Neurotrauma 2004; 21: 1371-1383. 
7 Kirshblum SC, Waring W, Biering-Sorensen F, Burns SP, Johansen M, Schmidt-Read M et al. Reference for the 2011 revision of the International Standards for Neurological Classification of Spinal Cord Injury. J Spinal Cord Med 2011; 34: 547-554.

8 Krassioukov A, Biering-Sorensen F, Donovan W, Kennelly M, Kirshblum S, Krogh K et al. International Standards to document remaining Autonomic Function after Spinal Cord Injury (ISAFSCI), First Edition 2012. Top Spinal Cord Inj Rehabil 2012; 18: 283-296.

9 American Spinal Injury Association. Autonomic Standards Assessment Form [Internet]. 2012 (cited 13 May 2015). Available from http://www.asia-spinalinjury.org/elearning/ ASIA Auto Stan Worksheet 2012.pdf.

10 Schuld C, Wiese J, Franz S, Putz C, Stierle I, Smoor I et al. Effect of formal training in scaling, scoring and classification of the International Standards for Neurological Classification of Spinal Cord Injury. Spinal Cord 2013; 51: 282-288.

11 Chafetz RS, Vogel LC, Betz RR, Gaughan JP, Mulcahey MJ. International Standards for Neurological Classification of Spinal Cord Injury: training effect on accurate classification. J Spinal Cord Med 2008; 31: 538-542.

12 Liu N, Zhou MW, Krassioukov AV, Biering-Sørensen F. Training effectiveness when teaching the International Standards for Neurological Classification of Spinal Cord Injury (ISNCSCI) to medical students. Spinal Cord 2013; 51: 768-771.

13 American Spinal Injury Association. Autonomic Standards Training E Program [Internet]. 2013 (cited 13 May 2014). Available from http://content.learnshare.com/ courses/120/468558/player.html.

14 Squair JW, le Nobel G, Noonan VK, Raina G, Krassioukov AV. Assessment of clinical adherence to the international autonomic standards following spinal cord injury. Spinal Cord 2015; 53: 1-5.
15 Biering-Sørensen F, Craggs M, Kennelly M, Schick E, Wyndaele JJ. International urodynamic basic spinal cord injury data set. Spinal Cord. 2008; 46: 513-516.

16 Whitehurst DGT, Suryaprakash N, Mittmann N, Noonan VK, Dvorak MFS, Engel L et al. Perceptions of individuals living with spinal cord injury toward preference-based quality of life instruments: a qualitative exploration. Value Heal 2013; 16: A38.

17 Tate DG, Kalpakjian CZ, Forchheimer MB. Quality of life issues in individuals with spinal cord injury. Arch Phys Med Rehabil 2002; 83 (Suppl 2): S18-S25.

18 Biering-Sørensen F, Charlifue S, DeVivo M, Noonan V, Post M, Stripling T, Wing P. Approved and finalized International Spinal Cord Injury (SCI) Data Sets. International Spinal Cord Injury Data sets. Spinal Cord 2006; 44: 530-534.

19 Fixsen D, Naoom S, Blase K, Friedman R, Wallace F. Implementation Research: A Synthesis of the Literature. University of South Florida: Tampa, FL, USA, 2005 pp 1-119.

20 Accreditation Canada. Qmentum Program: Spinal Cord Injury Acute Services, 2014.

21 Noonan V, Kwon B, Soril L, Fehlings M, Hurlbert R, Townson A et al. The Rick Hansen Spinal Cord Injury Registry (RHSCIR): a national patient-registry. Spinal Cord 2012; 50 (1): 22-27.

22 Cohen ME, Ditunno JF Jr, Donovan WH, Maynard FM Jr. A test of the 1992 International Standards for Neurological and Functional Classification of Spinal Cord Injury. Spinal Cord 1998; 36: 554-560.

23 Mulcahey MJ, Gaughan J, Betz RR, Vogel LC. Rater agreement on the ISCSCI motor and sensory scores obtained before and after formal training in testing technique. J Spinal Cord Med 2007; 30: 146-149.

24 American Spinal Injury Association. INSTeP [Internet]. 2013 (cited 26 November 2014). Available from http://lms3.learnshare.com/home.aspx. 